Onomástica Desde América Latina, n.4, v.2, julho - dezembro, 2021, p. 32 -53. ISSN 2675-2719 https://doi.org/10.48075/odal.v0i0.27324

\title{
Representação identitária, de memória e de retomada da história: topônimos de logradouros públicos da cidade de Balsas -MA
}

\section{Representation of identity, memory and recovery of History: toponyms of public places of the city of Balsas- MA}

\author{
Maria Célia Dias de Castro ${ }^{1}$ \\ http://orcid.org/0000-0003-3346-5990 \\ celialeitecastro@ hotmail.com \\ Universidade Estadual do Maranhão (UEMA) \\ Marta Helena Facco Piovesan ${ }^{2}$ \\ https://orcid.org/0000-0002-1136-5991 \\ martahpiovesan@hotmail.com \\ Universidade Estadual do Maranhão (UEMA)
}

\begin{abstract}
Resumo: Os nomes próprios de lugares, os topônimos, são elementos singulares do léxico da língua que, dentre suas várias funções como signo toponímico, prestam-se como indícios da história dos povos que os utilizam em suas interações verbais. Para além disso, são verdadeiros testemunhos dos diversos aspectos da memória e da identidade. Com esta perspectiva, este trabalho tem como objetivo principal verificar como os topônimos dos aglomerados urbanos da cidade de Balsas - MA manifestam as representações identitárias, de memória e de história de seus habitadores. A metodologia segue os pressupostos da onomástica, notadamente da toponímia, com uma análise descritiva das categorias identidade e memória entrelaçadas com a história, as quais são aplicadas aos topônimos de natureza antropocultural de base antroponímica, axionímica, coronímica e historionímica. Os resultados revelam que esses topônimos do sul do Maranhão expressam as acepções que abarcam a visão do mundo e da vida física e a visão da vida humana, os quais representam caracteres memorísticos e identitários dos vários povos que habitam este município, estabelecendo uma proximidade com essas transposições e instituições da língua.
\end{abstract}

Palavras-chave: Topônimos, Identidade, Memória, História, Balsas - MA.

Abstract: The proper names of places, toponyms, are singular elements of the lexicon of the language that, among its various functions as toponymic sign, lend themselves as evidence of the history of the people who use them in their verbal interactions. In addition, they are true testimonies of the various aspects of memory and identity. With this perspective, Thus, this paper has as main aims to verify how the toponyms of the urban agglomerations of the city of Balsas-MA manifest the identity, memorable and historic representations of its inhabitants. The methodology follows the assumptions of

\footnotetext{
${ }^{1}$ Doutora em Letras e Linguística (UFG). Professora do Departamento de Letras da Universidade Estadual do Maranhão - UEMA/Campus de Balsas. Professora do Programa de Pós-Graduação em Letras da Universidade Estadual da Região Tocantina do Maranhão - PPGLe - UEMASUL. Professora colaboradora PPGEC MINTER/DINTER UNIJUÍ e UNIBALSAS. Coordenadora projeto ATEMA, Apoio FAPEMA. ${ }^{2}$ Doutora em Letras e Linguística (UNISINOS). Professora da Universidade Estadual do Maranhão UEMA/Campus de Balsas. Professora pesquisadora do Projeto Atlas Toponímico do Maranhão - ATEMA.
} 
onomastics, notably toponymy, with a descriptive analysis of the categories identity and memory intertwined with history, which are applied to toponyms of anthropocultural nature, with base axionimic, coronimic and historionimic toponyms. The results reveal that these toponyms in the south of Maranhão express the meanings that encompass the world view and the physical life and the human life view, which represent memorable and identity characters of the various peoples that inhabit this municipality, establishing proximity with these transpositions and institutions of the language.

Key-words: Toponyms, Identity, Memory, History, Balsas-MA.

\section{Introdução}

Estudar o léxico de uma língua é a possibilidade de resgatar aspectos linguísticos, culturais e identitários de uma comunidade. Possibilita, também, conhecer concepções intrínsecas da realidade a que um dado grupo está inserido. O estudo dos topônimos pode oportunizar o conhecimento de fatos históricos, de características linguísticas e da etnologia da região a ser estudada, bem como os contatos que constituíram o lugar. Para Dick (1980: 08), "a toponímia reflete de perto a vivência do homem, enquanto entidade individual e enquanto membro do grupo que o acolhe". A autora afirma que os topônimos são "verdadeiros testemunhos históricos" nos diversos momentos de vida de uma população, transcendendo ao ato de nomeação, transformando-se em um instrumento de projeção temporal que grava o presente para o conhecimento das gerações futuras. Percebe-se que, para além do tempo vivido, são instrumentos de projeção humana, bem como transpõem os mais variados espaços geográficos.

À medida que os espaços vão sendo ocupados, surge a necessidade de o homem marcar seu território e para isso lança mão de nomes atribuídos aos lugares que retratam, muitas vezes, aspectos históricos de territorialização, além de revelar fatores ligados a crenças, à história e à cultura de uma comunidade. Os estudos onomásticos elucidaram a compreensão dos nomes de lugares e à vista disso foram fundamentais para compreender como os grupos sociais se organizam e se relacionam, numa intersecção linguística e sociocultural (BRANDÃO, ABBADE, 2016).

Balsas, uma cidade localizada ao Sul do Maranhão, teve uma colonização bem diferente do litoral maranhense, que foi colonizado por franceses, holandeses e portugueses e teve uma influência intensa dos negros africanos. O Sul foi colonizado mais tardiamente por vaqueiros, criadores de gado vindos de outros estados do Brasil como Piauí, Ceará e Pernambuco. Por volta da década de 1970, a região recebeu uma intensa corrente migratória do Rio Grande do Sul e mais tarde de outras regiões do Brasil e até 
Onomástica Desde América Latina, n.4, v.2, julho - dezembro, 2021, p. 32 -53. ISSN 2675-2719 https://doi.org/10.48075/odal.v0i0.27324

do exterior. Foi, então, dentro desse contexto de migração, no entrecruzamento de pessoas, que surgiu a cidade de Balsas cujas redes de trabalho e os estilos de vida do local foram recriados e modificados.

Esse novo contexto da história social deste município levantou questionamentos como: Como se percebem as representações dos sujeitos denominadores? Que caracteres constituem os traços memorísticos nestes nomes? Quais traços identitários podem ser verificados nos nomes dos aglomerados urbanos na cidade de Balsas-MA?

Como resultado destes questionamentos, no presente artigo realizou-se um recorte teórico e dos aspectos focalizados na realização da análise, como sugerem Teis, Seide e Lucas (2018), dos topônimos que nomeiam os aglomerados do núcleo urbano da cidade de Balsas-MA com base em seus traços culturais e nas representações da memória e da história como construtores de identidades de seus habitadores, por conseguinte, com o estudo linguístico ancorado em uma caracterização externa.

O corpus coletado pertence a uma ficha lexicográfica que contém os topônimos dos logradouros públicos da cidade de Balsas-MA. Estes topônimos foram organizados, segundo Dick (1990), em 27 taxonomias, 11 de natureza física e 16 de natureza antropocultural. Selecionaram-se as seguintes categorias de natureza antropocultural: antropotopônimos (nomes próprios individuais: Cândido Mendes, Coelho Neto); axiotopônimos (títulos e dignidades: Barão de Grajaú, Dom Pedro), corotopônimos (cidades, países, estados, regiões: Alto Alegre do Maranhão, Alto Alegre do Pindaré); e historiotopônimos (nomes de eventos ou personagens de cunho histórico: Bequimão, Carolina), por se compreender que esse conjunto de nomes aciona mais proximamente a cultura e a memória. Esses nomes passaram, portanto, a constituir o corpus do Atlas Toponímico do Estado do Maranhão - ATEMA.

Nesse sentido, o estudo dos topônimos aqui empreendido, além de identificar elementos físicos e humanos que constituem os nomes dos logradouros de Balsas, transformaram-se em testemunhos históricos, registrando fatos e ocorrências da formação dessa sociedade. E a memória é uma propriedade bastante significativa na constituição desses lugares e dos nomes que os identificam.

\section{Lugares e memória}

O termo memória, conforme Houaiss e Villar (2009), tem origem no latim memoria, ae e significa 'Faculdade de conservar e lembrar estados de consciência 
Onomástica Desde América Latina, n.4, v.2, julho - dezembro, 2021, p. 32 -53. ISSN 2675-2719 https://doi.org/10.48075/odal.v0i0.27324

passados e tudo quanto se ache associado aos mesmos'; 'aquilo que ocorre ao espírito como resultado de experiências já vividas, lembranças, reminiscência'.

A memória, segundo Le Goff (2003: 419), é a "propriedade de conservar certas informações, remete-nos em primeiro lugar a um conjunto de funções psíquicas, graças às quais o homem pode atualizar impressões ou informações passadas, ou que ele representa como passadas". Esse autor (2003: 422) relata a expansão da noção de memória e enfatiza a preocupação em controlar a memória e o esquecimento, de forma que esse fato é "uma das grandes preocupações das classes, dos grupos, dos indivíduos que dominaram e que dominam as sociedades históricas. Os esquecimentos e os silêncios da história são reveladores destes mecanismos de manipulação de memória coletiva". No desenvolvimento da história, nas sociedades ágrafas, ele lembra a preocupação com a memória coletiva e informa que ela era ordenada em três eixos: a idade coletiva do grupo, o prestígio das famílias dominantes e o saber técnico.

Le Goff (2003) registra que no Oriente antigo, por exemplo, após as grandes comemorações como fato demarcador da memória, surgiram as estelas ${ }^{3}$ e os monumentos simbólicos da memória, a exemplo do Naram-sin, na cidade de Susa, simbolizando o triunfo sobre os povos de Zagros; e a estela de Hammurabi, um rei babilônico (1792 a 1750 a.C.) que nela impôs seu conhecido código, que faz parte do acervo do Museu do Louvre, em Paris. Num aspecto da memória, as lembranças sob forma de inscrições eram materializadas em templos, nas praças, nas avenidas das cidades e até na beira das estradas e levavam os gregos e os romanos a rememorarem-nas via comemorações e perpetuação. Na historicização de Le Goff (2003), Goody apresenta como instrumentos marcantes para o desenvolvimento da memória nas civilizações antigas as listas lexicais, os glossários, os tratados de onomástica, fundamentando-se no pressuposto de que nomear é conhecer; e Gardiner informa acerca dos antigos tratados egípcios de onomástica datados de 1.100 a.C. inspirados provavelmente nos modelos sumérios. Com os gregos ocorre uma evolução da perspectiva de memória, em que a memória representa uma invenção, uma conquista do homem de seu passado individual, e de como, para o grupo, a história constitui uma retomada do passado coletivo. Os gregos até fizeram uma deusa da memória, Mnemosine, e Platão e Aristóteles compreendiam a memória como um componente da alma. Le Goff (2003) lembra que, remanescente dessa filosofia cristã,

\footnotetext{
${ }^{3}$ Coluna ou placa de pedra em que os antigos faziam inscrições, geralmente funerárias (HOUAISS, VILLAR, 2009).
} 
Onomástica Desde América Latina, n.4, v.2, julho - dezembro, 2021, p. 32 -53. ISSN 2675-2719 https://doi.org/10.48075/odal.v0i0.27324

há uma simbiose entre a morte e a memória; e na Idade Média, havia uma veneração aos velhos, por serem percebidos como guardadores de memória, o que os mantinha com muito prestígio e utilidade. No antigo Testamento, os livros do Deuteronômio $(8,11 ; 8$, 14) e de Isaías (44-21) convidam os fiéis a guardarem a memória que representa o conhecimento de Javé. Do Antigo ao Novo Testamento (última Ceia), a memória é lembrada como ação que invoca Javé e preserva a tradição, sendo o povo hebreu considerado por excelência um povo de memória. Santo Agostinho, em As confissões, traz um aprofundamento para a concepção de memória, de lugares de memória, procurando Deus no âmago de sua memória, embora não encontrando nenhuma imagem que o personifique.

$\mathrm{Na}$ contemporaneidade, a sociologia apresentou a memória sob um novo conceito na perspectiva, segundo Maurice Halbwachs (1950 apud LE GOFF, 2003: 466), de estar ligada "aos comportamentos, às mentalidades, novo objeto da nova história". Nesse cenário, Nora (1993) percebe a memória como as impressões daquilo foi vivido no passado pelos grupos, ou mesmo o que os grupos fazem daquilo que viveram no passado. Assim, a memória coletiva está envolta em questões da sociedade, das classes que são ou não dominantes, de maneira que essas classes se apropriam desses elementos nas lutas de poder e de sobrevivência. A memória é indubitavelmente um instrumento e um objeto de poder. A semelhança entre memória e história é discutida por Nora (1993: 09), que afirma: "Desde que haja rastro, distância, mediação, não estamos mais dentro da verdadeira memória, mas dentro da história". Portanto, esses indícios materiais registrados transpõem o nível da memória, posto que ela estaria humanizada nos grupos, em continuidade, vivificada dialogicamente entre a lembrança e o esquecimento, com as fragilidades a que essa humanização a expõe: deformações sucessivas, vulnerável a manipulações, a repentinas revitalizações, e sua reconstrução é problemática. A ausência causadora da lembrança, a memória tradicional, leva ao deslocamento, retomando o objeto deste estudo, essa ausência causadora de lembrança, de saudade, impacta nas interrelações sociais, na e pela linguagem, e leva à emergência de novos termos.

Nora (Idem) lembra que a memória tradicional vai desaparecendo e isso obriga a um acúmulo de materiais diversos: vestígios, testemunhos, documentos, imagens, discursos, sinais que comprovem aos sujeitos o que lhes existiu em tempos remotos.

Essa relação intrínseca tempo-sujeito muito interessa a Bergson (2006: 08), que explica sobre a duração do universo, "Quanto mais nos aprofundamos na natureza do tempo, mais compreendemos que duração significa invenção, criação de formas, 
Onomástica Desde América Latina, n.4, v.2, julho - dezembro, 2021, p. 32 -53. ISSN 2675-2719 https://doi.org/10.48075/odal.v0i0.27324

elaboração contínua do absolutamente novo". E toda essa criação e mudança se desenvolvem no espaço. Essa duração temporal é vista como movimento, ou seja, o tempo da lembrança, da memória, movimenta matérias psíquicas e linguísticas.

\begin{abstract}
$\mathrm{Na}$ verdade, o passado se conserva por si mesmo, automaticamente. Inteiro, sem dúvida, ele nos segue a todo instante: o que sentimos, pensamos, quisemos desde nossa primeira infância está aí, debruçado sobre o presente que a ele irá se juntar, forçando a porta da consciência que gostaria de deixá-lo de fora. (...) Quando muito, algumas recordações de luxo conseguem passar de contrabando pela porta entreaberta (...). Com efeito, que somos, que é nosso caráter, senão a condensação da história que vivemos desde nosso nascimento, antes dele até, já que trazemos conosco disposições pré-natais? (BERGSON, 2006: 47-48, Grifo do autor).
\end{abstract}

Como princípio de memória, Bergson (2006: 48-49) questiona se se trata de recuperar uma lembrança, um período de nossa história, em que nos afastamos do presente para nos recolocarmos no passado como se fotografássemos esse passado. Mas para Bergson (2006: 49) imaginar não é lembrar. Ele compreende a lembrança sendo a atualização de uma imagem que torna a viver; porém a imagem simples não remete ao passado a menos que ela tenha sido evocada do passado.

Como sugerem Le Goff, Nora e Bergson sobre a memória, ao escutar os nomes retomados de sujeitos passados e de outros espaços, ocorre um movimento em direção à imagem que esses nomes sugerem numa circularidade imagética que se retroalimenta da lembrança para a materialidade. A compreensão desses movimentos não é privilégio de filósofos da linguagem. Um passado vivificado nessa ancoragem de nomes é percebido pelas pessoas mais comuns, as quais dão importância significativa a esse fato e a ele se atêm para prestigiar suas memórias individuais e ressocializá-las via nomes de lugares.

Assim, a memória dos sujeitos e ou de um grupo é (r)estabelecida de forma consistente no ato de nomear os aglomerados humanos. É a história dos denominadores recuperada no tempo vivido numa inter-relação com os espaços em que se situam. Como se pode notar, os topônimos são como fios que se ligam uns aos outros num determinado espaço territorial e da linguagem e numa temporalidade, os quais, por sua vez, se ligam a fatores externos, que também são interligados a fatores cognitivos e assim, numa teia de circularidade e intricamento, estabelecem sua materialidade sistêmica de língua.

\title{
3 Lugares e identidade
}


Onomástica Desde América Latina, n.4, v.2, julho - dezembro, 2021, p. 32 -53. ISSN 2675-2719 https://doi.org/10.48075/odal.v0i0.27324

O termo identidade é de origem latina (identĭtas, -ātis), formado a partir do adjetivo "idem", com o significado de "o mesmo" e do sufixo -dade, indicador de um estado ou qualidade (HOUAISS, VILLAR, 2009). Os processos identitários estão sendo amplamente discutidos na contemporaneidade, principalmente no campo das Ciências Sociais e mais recentemente com subsídios da Linguística. A identidade é essencialmente conflituosa, envolvendo interação social, afetos, autoestima e jogos de poder. Para Moreno (2014: 07) "a identidade é uma categoria social discursivamente construída, expressa e percebida por diferentes linguagens: escritas, corporais, gestuais, imagéticas, midiáticas". Mais clara do que a noção de cultura, a identidade implica a produção de discursos portadores de signos de identificação. Nem sempre um grupo com uma cultura em comum reconhece-se ou é objeto de discursos identitários. A identidade estaria ligada, desta forma, à representação da cultura de um ou mais grupos humanos. A identidade cultural está diretamente ligada à definição de identidade, pois ela é a identificação essencial da cultura de um povo. O que um povo produz linguística, religiosa, artística, científica, moral e historicamente compõe o seu conjunto de produção cultural e esse conjunto tende a seguir certos padrões, o que cria um aspecto identitário para as culturas de determinadas sociedades.

A identidade é um processo que surge na interação dos seres humanos, é socialmente construída e rejeita qualquer visão relacionada a fatores biológicos e a categorizações sociais simplistas. Para Hall (2012), as identidades não definem indivíduos ou grupos étnicos / nacionais específicos, mas são exibidas e negociadas por meio do trabalho discursivo em interação com os outros. Isso reafirma o sentido de que as identidades não são vistas como algo que as pessoas têm, mas algo que as pessoas fazem em um processo de autoapresentação, de autoafirmação, de afirmação da própria imagem diante do outro, uma representação do eu histórico e cotidiano.

As velhas identidades, que por tanto tempo estabilizaram o mundo, estão em declínio, afirma Hall (2012), fazendo surgir novas identidades e fragmentando o indivíduo moderno visto até então como um sujeito unificado. Surge então a chamada “crise de identidade" devido a um processo inexorável de mudanças ocasionado pela globalização e pela intensa situação de mobilidade do ser humano. As distâncias diminuíram, as informações chegam rapidamente e o homem tem a possibilidade de atravessar fronteiras, buscar novos lugares, integrando-se e conectando-se a novas comunidades em novas combinações de espaço-tempo. 
Onomástica Desde América Latina, n.4, v.2, julho - dezembro, 2021, p. 32 -53. ISSN 2675-2719 https://doi.org/10.48075/odal.v0i0.27324

De um ponto de vista do surgimento de novas identidades e da própria fragmentação do indivíduo, antes percebido como unificado, lembra-se que a região de Balsas, no Sul do Maranhão, locus desta pesquisa, foi colonizada por migrantes e, mais tarde, na década de 1970, sofreu uma forte migração, principalmente de sulistas, intensificando-se nas décadas de 80 a 90 e transformando-se em uma fronteira agrícola. Sandri e Baú (2008) lembram que foi na década de 1970 que ocorreu o maior fluxo de migração interna do Brasil em função de uma política agrária favorável, de forma que os três estados da região Sul estabeleceram intensa migração em busca de terras para o cultivo agrícola nos estados do Acre, Amazonas, Bahia, Goiás, Maranhão, Mato Grosso, Piauí e Rondônia. Sendo assim, as migrações ocorridas em Balsas estão diretamente ligadas à construção de novas fronteiras agrícolas, consequentemente, de identidades sociais e das identidades dos indivíduos, sejam eles migrantes ou indivíduos naturais da região.

As migrações humanas têm papel principal na construção de sociedades híbridas, emergindo identidades culturais que não são fixas, mas que estão em transição e que são produto de complicados cruzamentos e misturas culturais cada vez mais comuns no mundo globalizado (HALL, 2012). As migrações possibilitam a formação de identidades que atravessam e intersectam fronteiras naturais compostas por pessoas que saem de sua terra natal e que negociam com outras culturas. As migrações, por vezes continuam retendo vínculos com seus lugares de origem e suas tradições, elas negociam com as novas culturas em que vivem, sem totalmente serem assimiladas por elas e sem perderem completamente suas identidades.

Nesse sentido, Canevacci (1996: 14) lembra o sucesso da perspectiva sincrética, na antropologia, cujo adjetivo disciplinar é a cultura em que "essa já não é vista como algo unitário, que compacta e liga entre si indivíduos, sexos, grupos, classes e etnias; mas sim é algo de bem mais plural, descentrado, fragmentário, conflitual" e o sincretismo "é o resultado de um contato intercultural e interlinguístico, por isso, ubíquo, pidgin, crioulo: é um contágio cultural, um vírus" (idem). Desse modo, ele assume o conceito de sincretismo como uma palavra-chave fundamental para se compreender todas essas transformações que ora ocorrem, com a própria globalização e localização que impacta nos modos tradicionais de produção de cultura.

Essas sociedades construídas a partir de processos migratórios não são unificadas, porque são o produto de várias histórias e culturas, porém interconectadas, sincréticas. 
Onomástica Desde América Latina, n.4, v.2, julho - dezembro, 2021, p. 32 -53. ISSN 2675-2719 https://doi.org/10.48075/odal.v0i0.27324

Pode-se pensar também em alteridade, noção que define o ser humano em uma relação que considera a diferença com o outro. Para Castro (2012: 148), essa noção aparece nas interações com os nomes que revelam a necessidade de "o homem se identificar a si e ao espaço em que vive, por meio das características étnicas que tornam possível distingui-lo, individualmente ou em grupos, de outras pessoas ou lugares, e os individualizam em relação a outros grupos ou indivíduos". Nesse sentido, a alteridade pode ser considerada não uma oposição, mas como um elemento constituidor, dentro de um grupo, da própria identidade.

A identidade é entendida sob o pressuposto da contemporaneidade baseada na igualdade e na diferença, afirma Hall (2014), não é um fenômeno fixo e imutável, mas uma realidade dinâmica em contínua evolução. Os processos de construção identitária não acontecem só no interior das pessoas, mas também se definem e se demarcam através das relações com outros objetos pertencentes à coletividade e nos vários âmbitos culturais onde os indivíduos se inserem. A formação da identidade é, portanto, determinada pelos contextos de cada coletividade, um processo que confere as caraterísticas específicas e os valores próprios de cada território. São os processos identitários assim construídos que concedem internamente personalidade e diferença a cada lugar, dando-lhe autonomia que distingue e diferencia os sujeitos perante os contextos globais uniformizadores (HALL, 2012). São essas características materiais e imateriais de um território que, embora mutáveis, contribuem para a (re) construção das identidades e são fundamentais para conferir originalidade e singularidade aos lugares e, consequentemente, diferenciá-los de outros lugares e territórios.

A nomeação de um lugar é uma necessidade de localização, mas também faz parte da cultura do ser humano. Esse ato vem carregado de intenções e sustenta características físicas do ambiente e subjetividades de seus denominadores. Desse modo, os topônimos podem representar valores, revelar traços culturais da memória e da identidade de um povo mediante as particularidades cristalizadas no termo toponímico. A motivação envolve uma complexa interação das condições do indivíduo e do ambiente total em que se encontra (DICK, 1980: 42).

Sendo assim, a análise das relações existentes entre a linguagem toponímica e a identidade do grupo que se apropria dela é uma questão que merece destaque. A nomeação de um logradouro é um traço cultural inquestionável, por isso construtor e externalizador de identidades, mas também se constitui como estratégia de poder, pois é 
Onomástica Desde América Latina, n.4, v.2, julho - dezembro, 2021, p. 32 -53. ISSN 2675-2719 https://doi.org/10.48075/odal.v0i0.27324

o resultado das leis, implementadas pelo poder público, que determinam a maneira como acontecerá a nomeação (SANTOS, 2020).

A nomeação de lugares traz consigo uma força construída pelo tempo, mas também pela aceitação dos que precisam designar um lugar pelo nome que seja conhecido por todos. Os seres humanos são presos ao espaço e ao tempo, e as designações espaciais e temporais fazem parte da identidade, tanto quanto o espaço é essencial à sobrevivência. Para Santos (2020: 613) "o lugar é resultado das experiências humanas. Sua existência é explicada pela maneira como as pessoas o percebem e lhe dão significado". Há uma familiaridade entre os indivíduos e os espaços que os circundam, ocasionando uma carga subjetiva e uma forte identificação entre o grupo e o topônimo.

A conotação geográfica da identidade não pode ser referida sob a mera dimensão espacial do fenômeno identitário, mas é, ao contrário, utilizada para representar aquelas ligações de pertença que criam "território". Cabe citar aqui também o conceito de identidade geográfica como uma "relação identitária que liga uma determinada comunidade ao seu espaço vivido" (CALDO, 1996: 285). Para o autor "espaço vivido" deve se entender como aquele momento de integração que conjuga no seu interior a dimensão física do espaço geográfico e aquela social do espaço relacional. O espaço não é apenas o cenário da ação humana, mas aquele carregado dos valores da cultura que ali se produz.

Acrescente-se, ainda, que a identidade territorial pode ser interpretada como sentido de pertença, identificação social, representação partilhada de um si coletivo. Pertencer a um território envolve muito mais do que nascer e morar nele, envolve, acima de tudo, o estabelecimento de relações sociais e a construção de uma identidade regional (PIOVESAN, 2020). Esse sentimento envolve a construção de uma identidade cultural que abrange hábitos, crenças e tradições ligadas ao cotidiano. Penna (2006) explica que o sentimento de pertencimento surge justamente da articulação da união entre a identidade territorial e a identidade cultural. A necessidade de pertencer, incluir-se e enraizar-se é comum especialmente no estabelecimento de novas fronteiras em que se traduz um sentimento de alteridade, de partícipes constitutivos de um todo com interesses de idêntica motivação ao de uma comunidade constituidora.

A função da memória de intermediar passado e presente possui um papel referencial importante para a (re) construção das identidades, em que elas são construídas na interação, a partir das diferenças e das negociações entre os indivíduos, situados em determinados lugares. 
Onomástica Desde América Latina, n.4, v.2, julho - dezembro, 2021, p. 32 -53. ISSN 2675-2719 https://doi.org/10.48075/odal.v0i0.27324

\section{Trilhando Lugares e identidade (trans) plantadas}

Retoma-se Moreno (2014) ao afirmar a identidade como uma construção social discursiva expressa por diferentes linguagens, bem como Le Goff (2003), que relembra a expansão da noção de memória e a preocupação das classes, dos grupos e dos indivíduos que dominaram e que dominam as sociedades históricas por controlarem a memória e o esquecimento.

E por meio de quais elementos linguísticos essas identidades e memórias se constroem discursivamente?

É o léxico a face da linguagem que torna possível produzir discursos com a noção de cultura, de identidade, de memória e de história, que implicam na produção de signos portadores dessas identificações. E os signos linguísticos em função toponímica se prestam perfeitamente a esse papel. Os topônimos dos aglomerados urbanos da cidade de Balsas-MA elencados neste trabalho foram selecionados de quatro dessas categorias (DICK, 1992): antropotopônimos, axiotopônimos, corotopônimos e historiotopônimos. Por esses nomes de lugares, reconstitui-se um caminho da memória transcendendo para a historicização, com a difusão e penetração dos nomes, dos arquivos memorísticos para uma difusão social via prática de linguagem. Essa prática acontece acionando-se as repetidas lembranças de momentos representativos de vida passada de maneira que atribuam formas sistematizadas aos novos espaços habitados. Lança-se mão da emergência da memória individual e de um grupo social, o que quer dizer, como Halbwachs o disse, "que há tantas memórias quantos grupos existem; que ela é, por natureza, múltipla e desacelerada, coletiva, plural e individualizada (2006 apud NORA, 1993: 09). A memória é um elemento constituinte do sentimento de identidade, tanto individual como coletiva, na medida em que ela é também um fator extremamente importante do sentimento de continuidade e de coerência de uma pessoa ou de um grupo em sua reconstrução de si (POLLAK, 1992).

Pode-se perceber variadas concepções na materialização da memória que trazem a vivacidade dos referenciais acionados aos nomes dos logradouros, organizados em dois grupos $^{4}$, primeiramente o do "mundo e da vida física" (o mundo e a natureza), que inclui

\footnotetext{
${ }^{4}$ Essa caracterização macro dos dois grupos tem base em Sapir (1980), que percebia o conjunto sígnico da língua de forma complexa em um quadro físico e social em que se organizam os grupos humanos. Dick (1990; 1992) seguiu essa orientação conceitual para organizar as 27 categorias com que classificou a
} 
Onomástica Desde América Latina, n.4, v.2, julho - dezembro, 2021, p. 32 -53. ISSN 2675-2719 https://doi.org/10.48075/odal.v0i0.27324

os aspectos geofísicos e os espaços já habitados; o segundo grupo, o da vida humana, que pode compreender: a dimensão religiosa, que inclui os elementos homem, religião e fé; a dimensão política, que inclui elementos como poder, privado e público, indivíduo e comunidade; a índole humana, em que se consideram aspectos como caráter, virtude, erro, arte, poesia; a justiça, compreendendo leis, normas, ordem, expressões jurídicas; a vida física humana, acionando aspectos físicos do homem, sentidos, saúde, doença; as ações humanas, incluindo-se as boas ou não; as condições econômicas, que levam em conta a riqueza e a pobreza; as experiências do conhecimento: ciência, conhecimento, escola, educação; e as movências humanas: as migrações e os acontecimentos históricos. Todos esses aspectos perceptíveis da materialização da memória manifestam-se via linguagem, notadamente nos antropotopônimos, axiotopônimos, corotopônimos e historiotopônimos, estabelecendo uma inter-relação com os aspectos culturais e identitários constituidores do homem, situado social e temporalmente nos espaços geográficos.

Dentro desse conjunto, pontua-se primeiramente os sobrenomes familiares em nomes de lugares, o que na taxonomia de Dick (1990) são categorizados como antropotopônimos. Segundo Seabra (2004: 353) em áreas de (i)migração, as nomeações de lugares são, frequentemente, homenagens a personalidades da classe política como a de vereadores. No sul do Maranhão, esse conjunto de nomes identifica a vida humana com sua dimensão política, que traz aspectos das esferas do governo, de poder público emanado de uma comunidade para um indivíduo, ao acionar, para denominar ruas, a memória de moradores antigos do município, tais como: Vereador Manoel João de Bastos, Isaac Martins, Vereador Manoel Leite, Vereador Salvador Coelho, Vereador Constâncio Coelho, Vereador Antônio Pires, Vereador Aldemar, Vereador Homérico, Antônio Ribeiro da Silva, Vereador T. Alencar Sampaio, Vereador Cláudio Pires, Vereador José Silva de Oliveira; nomes de prefeitos: José Leão, Jorge Cury, Joaquim Coelho, Prefeito Lauro Maranhão; presidentes: Presidente Prudente de Morais, José Sarney, Presidente Dutra e Juscelino.

Os nomes de parentes de políticos também são recorrentes, como Francisco Martins Santos, Vicente Dourado da Silva. Essas denominações revelam uma correlação com a consciência do poder, o poder da memória na dilatação do tempo dos sujeitos

toponímia brasileira, subdividida em dois grandes grupos, os de natureza física e os de natureza antropocultural. Nessa classificação, procurou-se apresentar aspectos que caracterizam o conjunto dos topônimos que portam traços referenciais mais evidentes da vida humana relacionados à cultura e à identidade. As categorizações micro foram parcialmente inspiradas no Dicionário de Sentenças Latinas e Gregas (TOSI, 1996). 
Onomástica Desde América Latina, n.4, v.2, julho - dezembro, 2021, p. 32 -53. ISSN 2675-2719 https://doi.org/10.48075/odal.v0i0.27324

referenciados e dos próprios sujeitos representados, pelo que apresentam a necessidade de mudança dos nomes existentes pelos que acionam a vida humana na dimensão política.

Outro grupo bastante representativo é o de nomes de cidadãos que reconhecidamente tinham as condições econômicas, que levam em conta a riqueza e a pobreza, notadamente os de muitas "posses", que certamente eram bem articulados socialmente, como Edísio Silva, Gomes de Sousa, Passondas Coelho, Domingos Almeida, Roberto Maranhão, Gesner Soares, Arão Ferreira Lima, José Nunes Silva, Francisco Lima. Diferentemente, observa-se o acionamento pouco recorrente de nomes de pessoas reconhecidas, porém de vida simples e em condição econômica que não é marcada pela riqueza, como Olavo C. Ribeiro, Eliezielda C. Rocha, Raimundo N. Almeida, Aprígio Alencar.

Percebe-se, sobremaneira, nessas denominações, um retorno ao passado, uma apreensão desse passado, num movimento que se manifesta em imagem presente, como salienta Bergson (2006), fazendo emergir das trevas para a luz do dia muitos desses nomes. É a presença viva e ao mesmo tempo simbólica da memória num movimento para a história, em que pesam "lembranças vagas, telescópicas, globais ou flutuantes, particulares ou simbólicas" (NORA, 1993: 9), lembranças sígnicas e sensíveis que se transferem e projetam nas cenas linguísticas do presente. As movências humanas surgem nesse cenário, as migrações e os acontecimentos históricos, com nomes que representam o mito fundador ou desbravador do lugar, como Antônio Jacobina; nomes históricos extraídos da história nacional e regional dos atuais habitadores deste município: Tiradentes, Bento Gonçalves e Garibalde Nunes.

Nomes de escritores maranhenses e brasileiros também constituem esse conjunto memorístico representando a índole humana, seu caráter e virtudes por meio da arte (poesia) com escritores/poetas, com Humberto de Campos, João Pessoa, Cassemiro de Abreu, Coelho Neto, Castro Alves. Bergson (2006: 49) percebe a memória e seus aspectos que se historizam e se plastificam:

Pouco a pouco, ela aparece como uma névoa que se condensasse; de virtual, passa ao estado atual; e, à medida que seus contornos vão se desenhando e sua superfície vai ganhando cor, tende a imitar a percepção. Mas permanece atada ao passado por suas raízes profundas, e se, depois de realizada, não se ressentisse de sua virtualidade original, se, ao mesmo tempo que um estado presente, não fosse algo que contrasta com o presente, nunca a reconheceríamos como lembrança [...] seguindo assim o progresso contínuo que a levou da obscuridade para a luz. 
Os nomes são da própria história e a história, como afirma Nora (1993: 9), "pertence a todos e a ninguém, o que lhe dá uma vocação para o universal. A memória se enraíza no conceito, no espaço, no gesto, na imagem, no objeto. A história só se liga às continuidades temporais, às evoluções e às relações das coisas”. Assim, a transição e a repetição dos nomes de lugares se processam concomitantemente na lembrança, e corporificam a identidade e a memória, pela relembrança e reencontro dos referenciais que são personificados e objetificados, em que esses elementos da língua levam ao reencontro da identidade e do pertencimento via designação.

Alguns poucos nomes de mulheres se fazem presentes: Milu Fonseca Santos, Emília Camera, Ritinha Pereira, historicizando o papel que representaram, trazendo essa parca visibilidade que tiveram no contexto de uma sociedade interiorana em que anteciparam as décadas do século XXI. Essas mulheres constituíram principalmente as experiências do conhecimento no âmbito da educação, consideradas boas ações humanas, profícuas e construtivas. São registrados, nesse conjunto toponímico, os nomes dos professores Melquíades Moreira, Profa. Virgínia Kury e Profa. Maria Amélia Bezerra (ainda residente na cidade). Com esses nomes de professores, a lembrança renasce bem mais viva, uma sensação de praesentia coletiva hipnotizadora.

Pessoas reconhecidas pela titularidade no campo social têm seus nomes acionados a boas ações humanas no que se refere à vida física humana, com os aspectos físicos do homem, saúde/doença, inserindo-se neste grupo os topônimos Dr. Didácio Santos e Dr. Rosy. O reconhecimento por boas ações humanas e no campo da justiça, da lei e da ordem constam nos axiotopônimos Dr. Justo Pedrosa, Dr. Renato Carvalho, Capitão Borba, Duque de Caxias, Coronel Fonseca, Coronel Silva Neto, Soldado Bruzaca. Com as boas ações humanas e na dimensão religiosa homem-fé constam os axiotopônimos D. Diogo Parodi, Dom Rino Carlesi, Dom Pedrito, Padre Franco, cujos nomes vêm rememorar um passado que passa a ser vivido em um eterno presente (NORA, 1993), a linguagem torna possível a atualização dessas ações como um fenômeno sempre atual.

Figura 1: Placa com axiotopônimos localizada no Centro de Balsas-MA 
Onomástica Desde América Latina, n.4, v.2, julho - dezembro, 2021, p. 32 -53. ISSN 2675-2719 https://doi.org/10.48075/odal.v0i0.27324

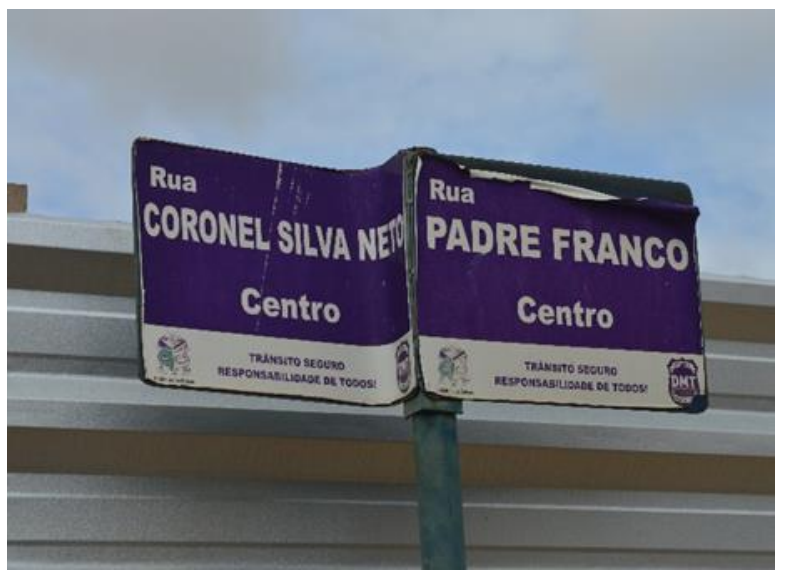

Fonte: as autoras.

É curioso o papel que realizam os axiotopônimos nesses referenciais de memória, trazendo a duração dos sujeitos do passado para o presente, dilatando o tempo vivido desses sujeitos e os perpetuando indefinidamente. Quanto mais ocorre uma observação refinada na natureza do tempo mais compreendemos que a duração dele também é invenção, significa criação de novas formas, explica Bergson (2006). Importa lembrar acerca dos guardadores de memória de que Le Goff fala, em que muito do que se sabe, principalmente sobre esses axiotopônimos e antropotopônimos, deve-se a eles e, de certa forma, ainda se vê as pessoas mais idosas como homens-memória e esses atributos lhes dão um considerável prestígio.

Portariam traços de alteridade e sincretismo os topônimos do sul do Maranhão?

Leva-se em conta, neste trabalho, que a alteridade não se opõe à identidade, mas a constitui pela convivência com a diferença, dentro de um grupo. Considera-se que os topônimos representam os elementos e o eu do sujeito histórico: suas memórias, sentimentos, o espaço em que vive ou viveu, de forma que distinga e sinta-se engajado em grupos ou lugares, que sinta a relação de pertença com outros grupos e lugares.

Em regiões com processo migratório mais recente, a antropotoponímia manifesta a intenção de demarcar a posse do território ocupado. Nesse processo, o nome de família se infla de uma carga simbólica e social de poder e a presença dos nomes de pessoas em forma de topônimo é uma maneira de cristalizar, no tempo, o respeito às personalidades e grupos escolhidos, assim como seus feitos como parte da lembrança coletiva do lugar (PHILIPPSEN, LIMA, 2018). De cristalizar esse respeito e admiração no tempo e no espaço. Dessas movências humanas, muitos nomes de migrantes sulistas têm sido 
Onomástica Desde América Latina, n.4, v.2, julho - dezembro, 2021, p. 32 -53. ISSN 2675-2719 https://doi.org/10.48075/odal.v0i0.27324

atribuídos aos logradouros públicos, como Dr. Irineu Alcides Bays, Leonardo Phillipsen e José Pugliesi.

Figura 2: Placa localizada no bairro de Fátima (Balsas-MA) com antropotopônimos de origem alemã e italiana

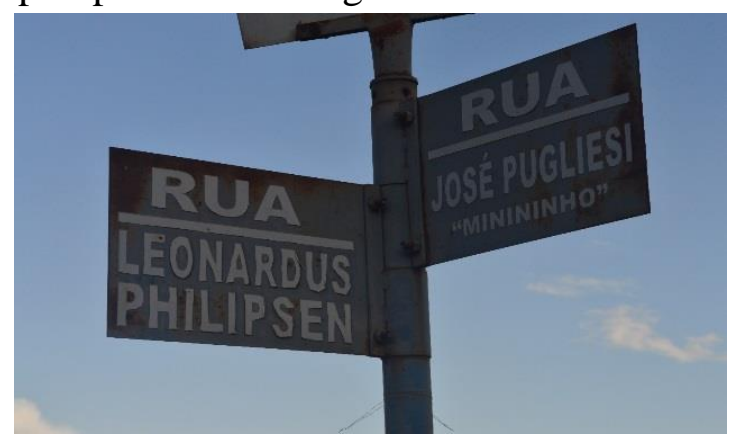

Fonte: as autoras.

Destaquem-se ainda as movências humanas por meio de processos migratórios dos sírio-libaneses representados em axiotopônimos como Profa. Virgínia Kury e Dr. Rosy Kury. Esses testemunhos linguísticos pelo léxico ratificam a possibilidade de o homem atravessar fronteiras, buscar novos lugares e integrar-se socialmente aos novos espaços. A atribuição desses nomes estabelece um engajamento identitário dos atuais habitadores com os espaços, via linguagem que os insere e historiciza nestes espaços. Ocorre ainda esse engajamento do mundo e da vida física desses sujeitos ao historicizarem seus espaços d'antes habitados: aproximando um distanciamento de um lá na proximidade de um aqui. Portanto, pode-se afirmar cabalmente que o léxico testemunha a alteridade nos nomes toponímicos dos aglomerados urbanos da cidade de Balsas-MA.

Acrescentem-se a este conjunto os corotopônimos de origem sulista que denominam logradouros públicos: Rio Grande do Sul, Santa Catarina, Paraná, Caxias, Gramado, Passo Fundo, Canastra, Florianópolis, Caçapava, Cruz Alta, Bento Gonçalves, Vacaria, Santa Maria, Bagé, Uruguaiana, Canoas, Alegrete, Perolas, São Miguel, Rio Pardo, Santa Rosa e São Borja. O uso recorrente dessa categoria revela processos identitários, como afirma Hall (2012), que concedem personalidade e diferença a esta cidade, dando-lhe particularidade, distinguindo e diferenciando tanto a cidade quanto seus sujeitos habitadores, mas também engajando o homem com seus referencias, com sua identidade, com sua história e com sua memória de forma a compensar a troca 
Onomástica Desde América Latina, n.4, v.2, julho - dezembro, 2021, p. 32 -53. ISSN 2675-2719 https://doi.org/10.48075/odal.v0i0.27324

dos espaços. Ou ainda, como nos lembra Nora (1993), os rastros, a distância e a mediação nos transportam para além da memória, da verdadeira memória, para dentro da história.

Tanto os corotopônimos quanto os nomes de migrantes sulistas como Dr. Irineu Alcides Bays, Leonardo Phillipsen, José Pugliesi dos descendentes de sírio-libaneses Profa. Virgínia. Kury e Dr. Rosy Kury revelam, pelo léxico, uma perspectiva sincrética da cultura em que essa, segundo Canevacci (1996: 14), é não unitária, compacta, mas plural, descentrada; são nomes resultantes desse contato intercultural e interlinguístico.

A presença dessa quantidade significativa de corotopônimos relativos ao sul do país revela negociação e aceitação, uma proximidade sociocultural, uma convergência cultural no território em que ora se situam. Esses nomes tornam mais visíveis os lugares transportados na memória e na história.

Haveria um sentimento de marginalização na história oficial do lugar-presente que traria essa necessidade de recuperar seu lugar-passado, a necessidade de sua constituição no espaço-passado que levaria a reencontrar suas origens no espaço-aqui e no tempoagora?

Esses nomes-lugares não estariam em um lugar-aqui se um sujeito constituído cultural e conscientemente não decidisse dessa transplantação se encarregar até socializar esses espaços-memória em espaços-nomes. É uma retomada de consciência de forma a melhor compreender e se adaptar ao presente. Acrescenta-se, ainda, que os migrantes trazem laços de sua terra natal, mas a vivência comunitária permite a sustentação de práticas culturais compartilhadas e valoradas positivamente. Segundo Penna (2006: 97), nesse sentido "fala-se de raízes que dizem respeito a uma referencialidade de espaço (territorial e/ou cultural), perdida com a migração, embora as práticas culturais não dependem tão diretamente da permanência na terra natal", tendo em vista que os lugares são fluidos e elas podem ser preservadas em outros espaços, recuperadas pela memória ou recriadas.

Pertencer a um território envolve muito mais do que nascer e morar nele, envolve, acima de tudo, o estabelecimento de relações sociais e a construção de uma identidade regional, da mesma forma que dominar o idioma e criar vínculos sociais não implica, necessariamente, a existência de um sentimento de pertencimento (PIOVESAN, 2020). Sentir-se pertencente a um lugar é construir uma identidade cultural e isso abrange hábitos, crenças e tradições ligadas ao cotidiano.

Retome-se a afirmação de Hall (2012) sobre o fato de as identidades não definirem indivíduos ou grupos étnicos específicos, mas serem negociadas discursivamente em 
Onomástica Desde América Latina, n.4, v.2, julho - dezembro, 2021, p. 32 -53. ISSN 2675-2719 https://doi.org/10.48075/odal.v0i0.27324

interação com os outros. Em tempos mais recentes, defrontamo-nos com culturas híbridas onde há um duplo sentimento de pertencimento, que pauta as relações individuais e coletivas e dá novos contornos à sociedade. Para Penna (2006), a construção de identidades está estreitamente ligada às condições de existência, à cultura e às relações sociais flexibilizadas pela manipulação dos referenciais disponíveis na sociedade em que o indivíduo vive em um dado momento histórico, disponíveis conforme a posição que ocupa e as práticas sociais que desenvolve.

Outros corotopônimos retomam espaços mais próximos, no próprio estado, e nem sempre já habitados pelos denominadores, como São Felix de Balsas, Feira Nova, Nova Colinas, Estreito, Alto Parnaíba, Benedito Leite, Loreto, São Domingo do Azeitão, Açailândia, Grajaú, Imperatriz, Sítio Novo, Maranhão, Mearim; ou fora do estado: Pernambuco, Bahia, Natal, Ceara, Sergipe, Recife, Maceió, Goiás, Rio de Janeiro; e Portugal, Egito, Veneza, Paraguai. Nessa materialização da memória, percebe-se uma convergência cultural, espontânea ou negociada na oficialização desses nomes, certa acomodação de convergências culturais que se refletem nesse sistema linguístico.

Merece destaque a grande ocorrência de numerotopônimos, ou seja, os nomes das ruas sem um "nome específico", identificados apenas por um número como no Bairro Cajueiro - Rua 9 e Rua 11 - esperando que os denominadores encontrem um nome que melhor identifique essas ruas. A denominação oficial, neste caso, não levou em consideração a motivação espontânea, utilizou-se de abstrações que representam uma quantificação do mundo material, fazendo com que os topônimos em questão se distanciassem dessas motivações de caráter histórico, memorístico e identitário "até se construir um novo uso para o mesmo objeto, tornado remotivado ou ressemantizado" (DICK, 2004). O uso desses topônimos neutros é próprio das sociedades em transformação e, conforme Hall (2014: 109), as pessoas não são e nunca serão unificadas, porque elas são, irrevogavelmente, o produto de várias histórias e culturas interconectadas. As identidades, então, estariam relacionadas com a questão da utilização dos recursos da história, da memória, da linguagem e da cultura para a produção daquilo no qual nos tornamos. Esses caminhos percorridos são chamados pelo autor de "rotas" que são negociadas no discurso, surgem na narrativização do "eu" e nos conduzem a uma sensação de pertencimento por meio do qual as identidades emergem a partir de "como nós temos sido representados" e "como essa representação afeta a forma como podemos representar a nós próprios". 
Onomástica Desde América Latina, n.4, v.2, julho - dezembro, 2021, p. 32 -53. ISSN 2675-2719 https://doi.org/10.48075/odal.v0i0.27324

O conjunto dos topônimos aqui analisados sob a perspectiva da memória - ou para mais além, da história - e da identidade lembra o forte entrecruzamento da linguagem do homem do presente com o passado, de como a linguagem está vinculada ao pensamento e de como o pensamento se constitui de lembranças, de memória. Os grupos axiotoponímicos, corotoponímicos e historiotoponímicos portam, em sua essência, referenciais que são representação do passado, da memória, da própria personificação dos sujeitos nesses grupos de topônimos. Trazem o passado para o instante e a linguagem presentes, acionam o homem, a terra, histórias, sentimentos que são caros aos denominadores e a (re) criação e retomada pela linguagem revelam como nos constituímos como sujeitos sociais e históricos. A linguagem é, talvez, o maior instrumento de traços identitários do homem, vinculado a um determinado território.

\section{Uma palavra adicional}

Essas reflexões verificam como se manifestam aspectos da identidade e da memória dos habitadores na formação toponímica dos logradouros da Cidade de Balsas, Sul do Maranhão, uma região formada por diferentes ciclos migratórios que aconteceram mais abundantemente na década de 1970, com a chegada de migrantes sulistas e se intensificaram a partir da formação de uma fronteira agrícola.

A cidade demonstrou ser um território constituído de correlações: diversos bairros, praças, ruas, elementos importantes que unem um certo número de pessoas, propiciando a criação de múltiplas correlações e representações memorísticas e identitárias. Dessa forma, pode-se afirmar que essas identidades são formadas dentro de um contexto que envolve o ambiente onde mora a família, nas relações com amigos e vizinhos, em lugares que apresentam uma série de significados gerados pelos encontros das pessoas. Verifica-se ainda que a alteridade, o sincretismo e a acomodação de convergências são traços de representação identificados nos grupos de topônimos dos aglomerados urbanos de Balsas e que esses nomes trazem para a materialidade da língua principalmente a cultura, a história e o torrão natal dos sujeitos denominadores.

Observa-se como caracteres que constituem traços memorísticos nestes nomes o fato de os lugares e os nomes designados serem resultantes das experiências humanas e das relações com quem lhes rodeia no cotidiano. Nesse contexto, os topônimos surgem para identificar o grupo que se utiliza deles por meio de uma forte relação de 
Onomástica Desde América Latina, n.4, v.2, julho - dezembro, 2021, p. 32 -53. ISSN 2675-2719 https://doi.org/10.48075/odal.v0i0.27324

subjetividade, marcando traços culturais inconfundíveis, mas também estratégias de poder. Ademais, as nomeações e as motivações para a escolha dos nomes de lugares permitem conhecer muito sobre o território e sua formação e ao mesmo tempo resgatar as memórias e as construções identitárias do local.

Percebe-se que as ruas de Balsas mostram uma significativa maioria de antropotopônimos, refletindo um contexto cultural específico marcado pelas relações de poder ligadas a personalidades da classe política ou de cidadãos comuns que tinham posses ou até mesmo parentes de políticos. Nesse cenário, nomes de desbravadores e nomes históricos também aparecem marcando a relação que os moradores que vivem ou que viveram tiveram com o cotidiano. Alguns logradouros se sobressaíram pela imposição de nomes por parte do poder público, mas em outros, a força da memória popular coletiva, por meio do uso cotidiano do nome conhecido, se sobressaiu ajudando a compreender mais sobre a história do lugar e assim preservar a memória.

A região sul maranhense, marcada pela mistura de muitas pessoas vindas de diferentes lugares, traduz um processo de (re) construção de referenciais de vida, pois a concepção de identidade não pode ser essencialista, visto que a identidade social construída não é fixa e imutável, mas está sempre em transformação. Em virtude dessas mudanças nos processos relativos à identidade social, Balsas apresenta tantos topônimos indefinidos, os numerotopônimos, topônimos neutros que estão à espera de um nome.

Ao final, em vista dos resultados obtidos sobre as representações identitárias, de memória e de retomada da história nos topônimos da cidade de Balsas-MA, é possível concluir que os nomes dos espaços urbanos são testemunho vivo da história dos povos que os habitam e que esses nomes são registros sentimentais e descritivos de memória e de identidade. Que o indivíduo é responsável pela condução de sua história e pode construir novas identidades ao longo de sua existência motivado por correlações, fragmentações e rupturas, permitindo um novo reconhecimento nas interações sociais e espaciais de que faz parte.

Recebido em 04/05/2020

Aceito em 23/05/2021

Publicado em em 25/08/2021

\section{Referências}

BERGSON, Henri. (2006). Memória e Vida. Textos escolhidos por Gilles Deleuze. Trad. Claudia Berliner. São Paulo: Martins Fontes. 
BRANDÃO, Analídia dos Santos.; ABBADE Celina Márcia de Souza. (2016). Os antropotopônimos na Bahia de Todos os Santos: uma análise social e linguística. Revista GTLex, 1, n.2, 312-325

CALDO, Costantino. (1996). Geografia umana, Palermo, Palumbo.

CANEVACCI, Massimo. (1996). Sincretismo: uma exploração das hibridações culturais. Trad.: Roberta Barni. São Paulo: Instituto Cultural Ítalo Brasileiro; Instituo Italiano di Cultura.

CASTRO, Maria Célia Dias de. (2012). Maranhão: sua toponímia, sua história, $474 \mathrm{f}$. Tese (Doutorado em Linguística) - Faculdade de Letras, Universidade Federal de Goiás, Goiânia.

DICK, Maria Vicentina de Paula do Amaral. (1980). Toponímia e Antroponímia no Brasil. Coletânea de Estudos. São Paulo: Serviço de Artes Gráficas/FFLCH/USP.

DICK, Maria Vicentina de Paula do Amaral. (2004). Rede de conhecimento e campo lexical: hidrônimos e hidrotopônimos na onomástica brasileira. In: ISQUERDO, A. N.; KRIEGER, M. G. (Org.). As ciências do léxico. Lexicologia, lexicografia, terminologia. v. II. Campo Grande: UFMS, 121-130.

DICK, Maria Vicentina de Paula do Amaral. (1990). A motivação toponímica e a realidade brasileira. São Paulo, Arquivo do Estado.

DICK, Maria Vicentina de Paula do Amaral. (1992). Toponímia e antroponímia no Brasil: coletânea de estudos. 3. ed. São Paulo: FFL/USP.

HOUAISS, Antonio. VILLAR, M. S. (2009). Dicionário Houaiss de Língua Portuguesa. Elaborado pelo Instituto Antônio Houaiss de Lexicografia e Banco de Dados da Língua Portuguesa S/C Ltda. Rio de Janeiro: Objetiva.

LE GOFF, Jacques. (2003). História e memória. Trad. Bernardo Leitão. Campinas, SP: Editora da UNICAMP.

HALL, Stuart. (2012). A identidade cultural na pós-modernidade. Rio de Janeiro: DP\&A.

HALL, Stuart. (2014). Quem precisa de identidade? In: SILVA, T. T. Identidade e diferença: a perspectiva dos estudos culturais (org.). Petrópolis: Vozes, 247-264.

MORENO, Jean Carlos. (2014). Revisitando o conceito de identidade nacional. In: RODRIGUES, Cristina Carneiro. LUCA, Tania Regina de. GUIMARÃES, Valéria. orgs. Identidades brasileiras: composições e recomposições [online]. São Paulo: Editora UNESP; São Paulo: Cultura Acadêmica, 7-29. Desafios Contemporâneos collection. ISBN 978-85-7983-515-5.

NORA, Pierre. (1993). Entre memória e história: a problemática dos lugares. Trad. Yara Aun Khoury. In.: Revista do programa de estudos pós-graduados em história e do departamento de história - Projeto história, 10, PUC/SP. 
Onomástica Desde América Latina, n.4, v.2, julho - dezembro, 2021, p. 32 -53. ISSN 2675-2719 https://doi.org/10.48075/odal.v0i0.27324

PENNA, Maura. (2006). Relatos de migrantes: questionando as noções de perda de identidade e desenraizamento. In: SIGNORINI, Inês. (org.). Lingua(gem) e identidade. Campinas: Mercado das Letras, 89-111.

PIOVESAN, Marta Helena Facco. (2020). A construção de identidades: (des)encontros no sul do Maranhão. Curitiba: CRV.

PHILIPPSEN, Neusa Inês. LIMA, José Leonildo. (2018). Diversidade e Variação Linguística em Mato Grosso, Cáceres: Editora Unemat.

POLLAK, Michael. (1992). Memória e Identidade Social. Estudos Históricos, Rio de Janeiro, vol. 5, 10, 200-212.

SAPIR, Edward. (1980). A Linguagem. São Paulo: Perspectiva.

SANDRI, Márcia Meurer. BAÚ, Sandra. Cristina Schuster. (2008). Balsas, palco de integração social: o encontro do sertanejo e do gaúcho. Imperatriz-MA: Ética.

SANTOS, Luiz Eduardo Neves dos. (2020). Toponímia e Lugar: os significados múltiplos dos logradouros públicos no município de Grajaú, MA. Caderno de Geografia, 30,62 .

SEABRA, Maria Cândida Trindade Costa de. (2004). A formação e a fixação da Língua Portuguesa em Minas Gerais: a toponímia da Região do Carmo. Tese de Doutorado, UFMG: Belo Horizonte.

TEIS Denize Terezinha. SEIDE Marcia Seide. LUCAS Patrícia (2018) Os topônimos na paisagem linguística da Av. Zelina em São Paulo: um encontro na interdisciplinaridade. Revista do GELNE. 20 (2), 16-29.

TOSI, Renzo. (1996). Dicionário de sentenças latinas e gregas. (tradução Ivone Castilho Benedetti) São Paulo: Martins Fontes. 